\title{
Liquid Structure and Solubility of Sparingly Soluble Salts in Water
}

T. G. OWE B ER G

Avesta Jernverks A.B, Avesta, Sweden

\begin{abstract}
The theoretical formula for the solubility of solids in liquids assum. ing the solution to be ideal, is applied to aqueous solutions of sparingly soluble salts. The process of dissolution involves chemical reaction between salt and water. The equilibrium constants for a few such reaction equilibria are computed from the coordination numbers of the liquid structure. The results are compared with experimental data on silver halides, lead halides, and $\mathrm{Ag}_{2} \mathrm{O}$.
\end{abstract}

\section{THEORY}

When a system is in equilibrium, its free energy is a minimum. For instance, when two phases are in equilibrium with one another, there is no change in the free energy of the entire system, when matter is transferred from one phase to the other. We will apply this principle to the solubility of a sparingly soluble salt in water.

We will consider the process of dissolution as consisting of two steps. In the first step the solid salt is transformed from the solid into the liquid state. In the second step the liquid salt is mixed with the liquid water. We will assume that the mixture is ideal, $i . e$. there is no heat of mixing, and the entropy of mixing is equal to $R$ times the logarithm of the mole fraction $X$ of the salt (Raoult's law). From the fundamental principle

we thus obtain

$$
\Delta F=0
$$

$$
\Delta F_{m}=-T \Delta S_{m}=-\Delta F_{t}
$$

when $m$ denotes mixing and $f$ fusion.

With Raoult's law

we have from (2)

$$
\Delta S_{m}=-R \ln X, \Delta E_{m}=0
$$

$$
X=e^{-\frac{\Delta F_{f}}{R T}}
$$


Applying the principle (1) to the process of melting, we find at the melting point $T_{t}$

Hence,

$$
\Delta F_{t}=\Delta E_{f}-T_{f} \Delta S_{f}=0
$$

$$
X=e^{-\frac{\Delta E_{f}}{R}\left(\frac{1}{T}-\frac{1}{T_{f}}\right)}
$$

This is the familiar formula for the solubility of a solid in a liquid on the assumption that the solution is ideal.

Few aqueous solutions are ideal. As a rule the water reacts with the salt. This reaction is accompanied by a free energy of reaction $\Delta F_{\text {e }}$ which must be included in (1). We will write $\Delta F_{e}$ in the form

and assume that

$$
\Delta F_{e}=\Delta E_{e}-T \Delta S_{e}
$$

$$
\Delta S_{e}=\frac{\Delta E_{e}}{T_{f}}+\Delta S_{\text {struct }}
$$

Hence,

$$
\frac{\Delta F_{e}}{T}=-\Delta S_{\text {struct. }}+\Delta E_{e}\left(\frac{1}{T}-\frac{1}{T_{f}}\right)
$$

The entropy change $\Delta S_{\text {struct. }}$ derives from the structural change involved in the reaction,

$$
\Delta S_{\text {struct. }}=R \ln W
$$

when $W$ denotes the ratio of the numbers of ways in which the two states, before and after the reaction, may be realized.

Including $\Delta E_{c}$ and $\Delta E_{f}$ in the heat of solution $\Delta E_{s}$ of the solid salt we have thus with (1), (6), (9) and (10)

$$
X=W e^{-\frac{\Delta E_{s}}{R}\left(\frac{1}{T}-\frac{1}{T}\right)}
$$

This formula is valid for a solution such that

$$
\Delta S_{m}=-R \ln X
$$

i. e. for a sufficiently dilute solution.

Since there are 55.55 moles of water per litre of pure water, and since the concentration of the water is not appreciably changed by the presence of a sparingly soluble salt in the solution, we may express the solubility in mole/ litre instead of mole fraction by rewriting (11) in the form

$$
c=55.55 W e^{-\frac{\Delta E_{s}}{R}\left(\frac{1}{T}-\frac{\dot{1}}{T_{t}}\right)}
$$

Acta Chem. Scand. 7 (1953) No. 10 
We will now consider reactions of the types

$$
\begin{aligned}
\mathrm{AB}+\mathrm{H}_{2} \mathrm{O} & \rightleftharpoons\left(\mathrm{AB} \mathrm{H}_{2} \mathrm{O}\right) \\
\mathrm{AB}+\mathrm{H}_{2} \mathrm{O} & \rightleftharpoons \mathrm{AOH}+\mathrm{HB}
\end{aligned}
$$

The equilibrium is characterized by its equilibrium constant

or with (9)

$$
K=e^{-\frac{\Delta F_{e}}{R T}}
$$

$$
K=W e^{-\frac{\Delta E_{e}}{R}\left(\frac{1}{T}-\frac{1}{T_{l}}\right)}
$$

We may therefore calculate $K$ by way of calculating $W$ from the structure of the liquid. Instances of such calculations will be given in section 3.

\section{EMPIRICAL RELATIONS}

In the following we will apply these formulae to a few cases of sparingly soluble salts. However, before we do so we will consider the experimental data and derive corresponding empirical formulae which we will then interpret by comparing them with the theoretical formulae and by considering the reactions involved. The data employed have been taken from Landolt-Börnstein and from the Handbook of Chemistry and Physics. The values of $-\Delta E_{s}$ have been taken from those tables ("observed"), from a plot of $\log c=$ $=f\left(\frac{1}{T}\right)$ "(from curve"), or computed according to the rule of heats of formation in dilute solution derived elsewhere ${ }^{1}$ and from the observed heats of formation in the solid state ("computed").

Tables 1 and 2 give data for silver and lead halides, respectively.

Table 1. Solubility of silver halides.

\begin{tabular}{lcccc}
\multicolumn{1}{c}{ Salt } & $\mathrm{AgF}$ & $\mathrm{AgCl}$ & $\mathrm{AgBr}$ & $\mathrm{AgI}$ \\
$-\Delta E_{s}$ (computed) & +4.3 & -15.9 & -20.2 & -26.5 \\
$-\Delta E_{s}$ (from Fig. 2 ) & - & $-2 \times 7.79$ & - & - \\
$c$ mole/litre at 16 & $\mathbf{1 4}$ & $9.70 \cdot 10^{-6}$ & $\mathbf{5 . 6 0} \cdot 10^{-7}$ & $\mathbf{6 . 4 8 . 1 9 ^ { - 8 }}$ \\
10log $c$ & $0.146+1$ & $0.987-6$ & $0.748-7$ & $0.812-9$ \\
$T_{f}$ (observed) & 708 & 728 & 703 & 830 \\
$T_{f}$ (from Fig. 1) $*$ & 1410 & 1410 & 1410 & 1410
\end{tabular}

* $T_{f}$ is regarded as an empirical constant the significance of which will be discussed in section 4.

Table 2. Solubility of lead halides.

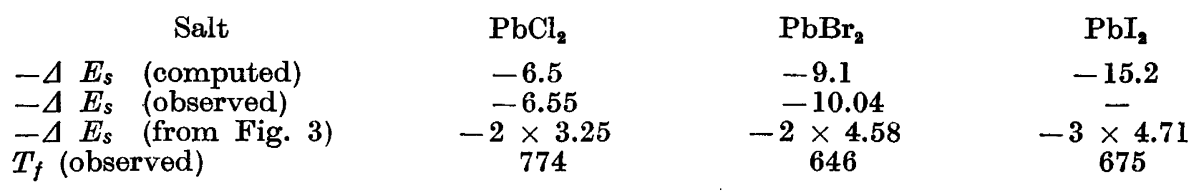

Acta Chem. Scand. 7 (1953) No. 10 


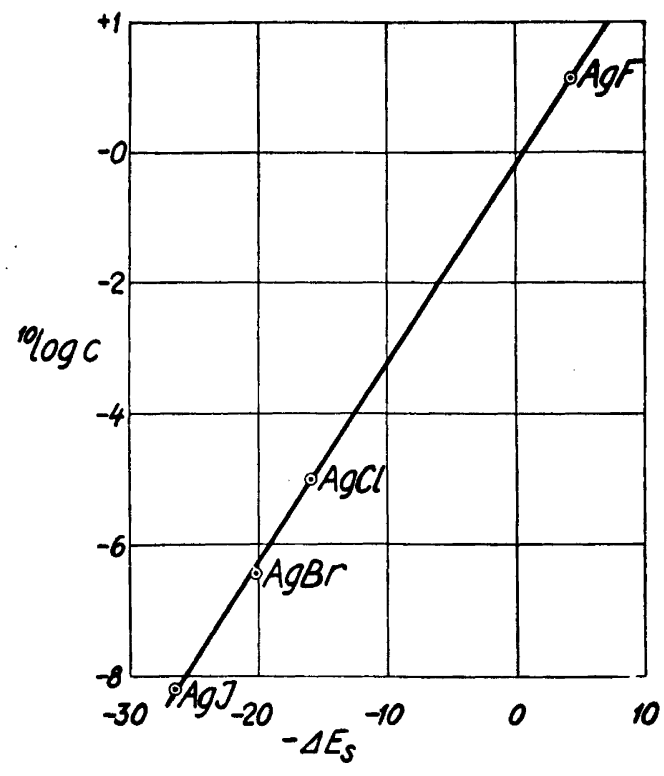

Fig. 1. ${ }^{10} \log \mathrm{c}=\mathrm{f}\left(-\Delta E_{s}\right)$ for silver halides at $16^{\circ}$.

Fig. 1 shows a plot of ${ }^{10} \log c=f\left(-\Delta E_{s}\right)$ on the observed data of $c$ and the computed values of $-\Delta E_{s}$. Fig. 2 shows a plot of ${ }^{10} \log c=f\left(\frac{1}{T}\right)$ for AgCl. The two curves satisfy the formula

$$
c=0.67 e^{-\frac{\Delta E_{s}}{2 R}\left(\frac{1}{T}-\frac{1}{T_{t}}\right)}
$$

where $T_{t}=1410^{\circ} \mathrm{K}$.

Fig. 3 shows plots of ${ }^{10} \log c=f\left(\frac{1}{T}\right)$ for $\mathrm{PbCl}_{2}, \mathrm{PbBr}_{2}$ and $\mathrm{PbI}_{2}$. Inserting the values of $T_{f}$ given in Table 2 we obtain the following formulae

$$
\begin{aligned}
& \mathrm{PbCl}_{2}: \quad c=1.15 e^{-\frac{3.25}{R}\left(\frac{1}{T}-\frac{1}{T}\right)} \\
& \mathrm{PbBr}_{2}: \quad c=1.70 e^{-\frac{4.58}{R}\left(\frac{1}{T}-\frac{1}{T_{f}}\right)} \\
& \mathrm{PbI}_{2}: \quad c=0.158 e^{-\frac{4.71}{R}\left(\frac{1}{T}-\frac{1}{T}\right)}
\end{aligned}
$$

Acta Chem. Scand. 7 (1953) No. 10 
Fig. 2. ${ }^{10} \log \mathrm{c}=\mathrm{f}\left(\frac{1000}{T}\right)$ for $\mathrm{AgCl}$.
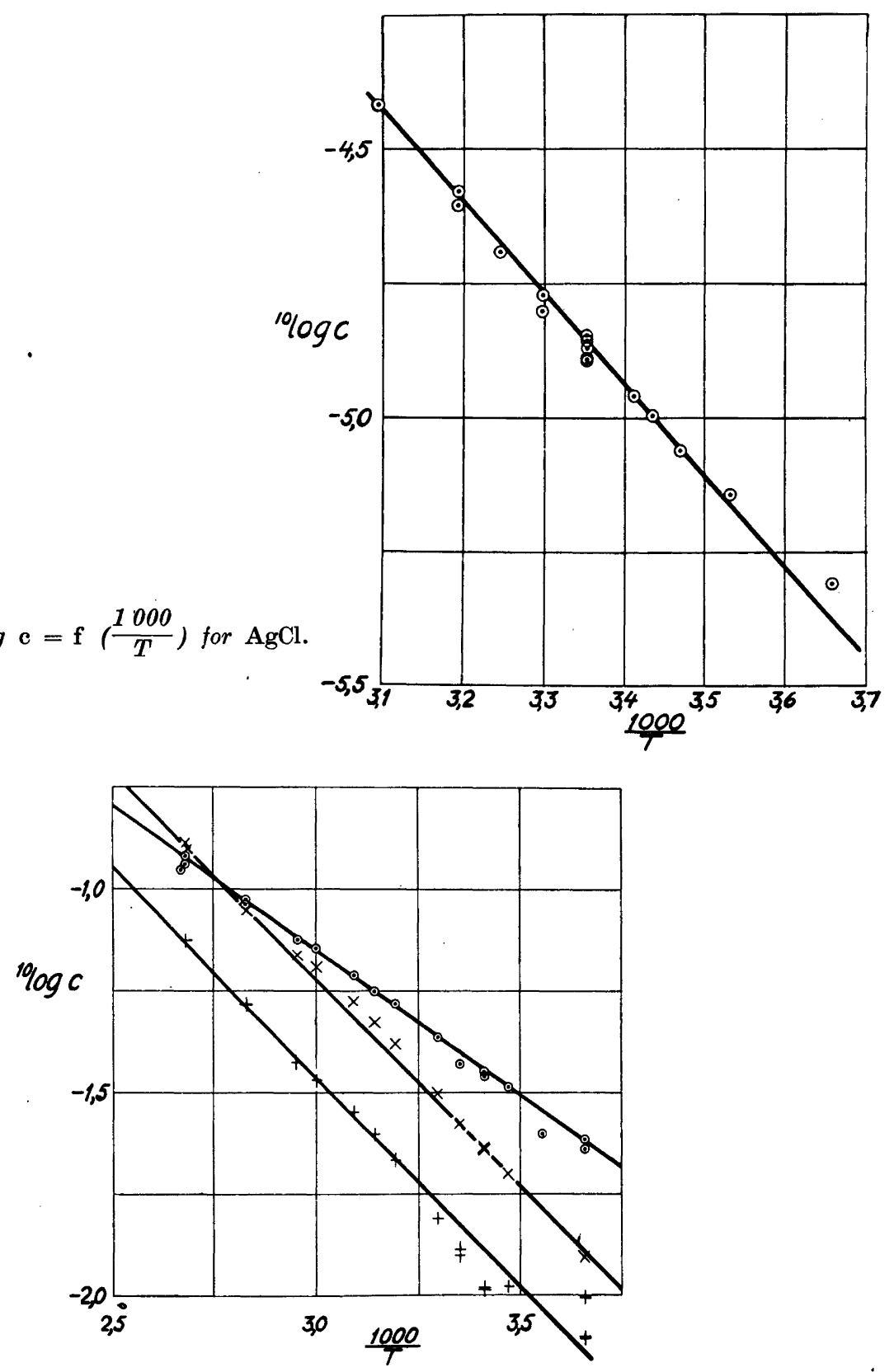

Fig. 3. ${ }^{10} \log \mathrm{c}=\mathrm{f}\left(\frac{1000}{T}\right)$ for $\mathrm{PbCl}_{2}(\odot)$ and $\mathrm{PbBr}_{\mathbf{2}}(\times)$.

${ }^{10} \log \mathrm{c}+1.9=\mathrm{f}\left(\frac{1000}{T}\right)$ for $P b I_{2}(+)$.

Acta Chem. Scand. 7 (1953) No. 10 


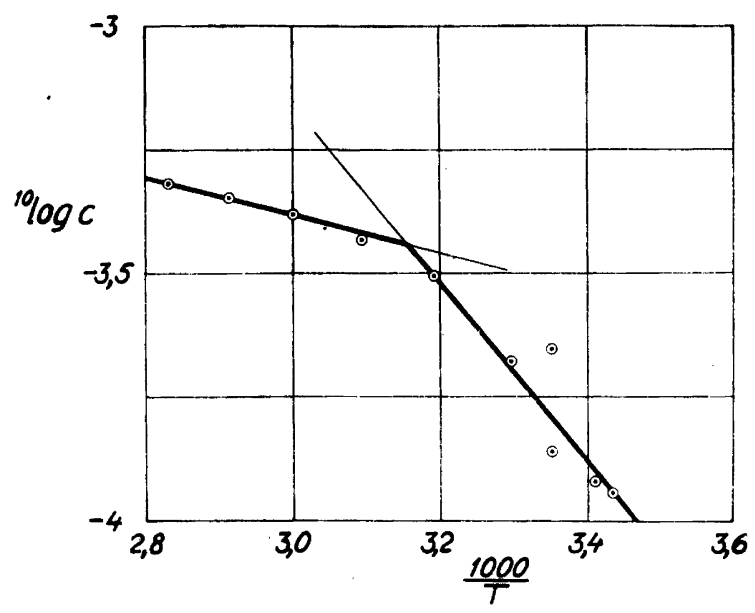

Fig. 4. ${ }^{10} \log \mathrm{c}=\mathrm{f}\left(\frac{1000}{\mathrm{~T}}\right)$ for $A g_{\mathrm{z}} \mathrm{O}$.

Fig. 4 shows ${ }^{10} \log c=\mathrm{f}\left(\frac{1}{T}\right)$ for $\operatorname{Ag}_{2} O$. The slope of this curve gives $\Delta E_{s}=$ $=8.2$ for $T<317^{\circ} \mathrm{K}$. Inserting $T_{r}=1410^{\circ} \mathrm{K} *$ we obtain from the curve

$$
\mathrm{Ag}_{2} \mathrm{O}: c=8.7 e^{-\frac{8.2}{R}\left(\frac{1}{T}-\frac{1}{1410}\right)}
$$

\section{COMPARISON OF THEORETICAL AND EMPIRICAL FORMULAE}

\section{A. Solubility of $\mathrm{Ag}_{2} \mathrm{O}$}

When a hypothetical liquid $\mathrm{Ag}_{2} \mathrm{O}$ is mixed with liquid water, it is built into the structure of the water. Each $\mathrm{Ag}_{2} \mathrm{O}$ molecule is surrounded by $\mathrm{H}_{2} \mathrm{O}$ molecules and bound to those with $\mathrm{O}-\mathrm{H}-\mathrm{O}$ and $\mathrm{Ag}-\mathrm{O}$ bonds. Fig. 5 illustrates this structure schematically.

The breaking of the $\mathrm{O}-\mathrm{H}-\mathrm{O}$ bond as indicated in Fig. 5 brings about the reaction

$$
\mathrm{Ag}_{2} \mathrm{O}+\mathrm{H}_{2} \mathrm{O} \rightarrow(\mathrm{AgOH})_{2} \text {. }
$$

The re-formation of the same bond leads to the reaction

$$
(\mathrm{AgOH})_{2} \rightarrow \operatorname{Ag}_{2} \mathrm{O}+\mathrm{H}_{2} \mathrm{O} \text {. }
$$

We will therefore consider the equilibrium

$$
\mathrm{Ag}_{2} \mathrm{O}+\mathrm{H}_{2} \mathrm{O} \rightleftharpoons(\mathrm{AgOH})_{2} \text {. }
$$

* This choice of $T_{f}$ will be discussed in section 4. 


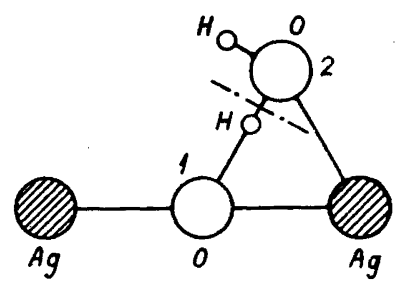

Fig. 5.

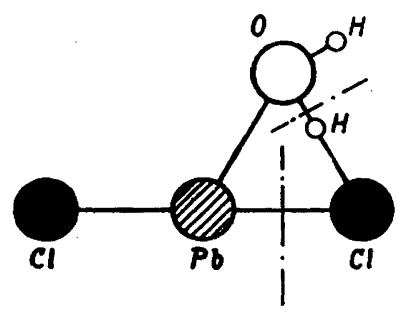

Fig. 7.

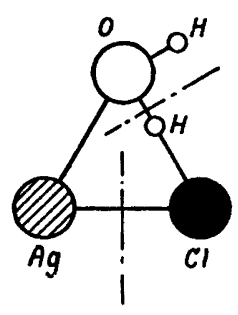

Fig. 6 .

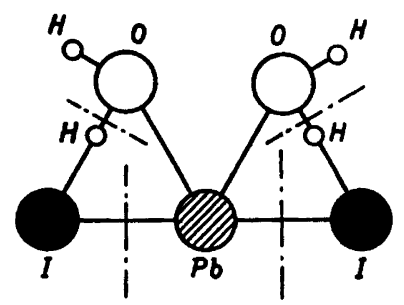

Fig. 8 .

When the bond is broken, the two $\mathrm{OH}$ groups can form new bonds with surrounding $\mathrm{H}_{2} \mathrm{O}$ molecules. In pure water each $\mathrm{H}_{2} \mathrm{O}$ molecule or $\mathrm{OH}$ group is surrounded by 4 neighbors. We will assume this to be the case with the $\mathrm{OH}$ groups of $(\mathrm{AgOH})_{2}$ as well. The number of ways in which new bonds can be formed is thus, 2 for oxygen atom No. 1 and 3 for oxygen atom No. 2. Hence,

and

$$
\frac{1}{W}=2 \times 3=6, \Delta S_{\text {struct. }}=-R \ln 6
$$

$$
c_{(\mathrm{AgOH})_{2}}=\frac{55.55}{6} e^{-\frac{\Delta E_{s}}{R}\left(\frac{1}{T}-\frac{1}{T_{f}}\right)}=9.3 e^{-\frac{\Delta E_{s}}{R}\left(\frac{1}{T}-\frac{1}{T_{f}}\right)}
$$

B. Solubility of silver halides

The equilibrium is

$$
\mathrm{AgX}+\mathrm{H}_{2} \mathrm{O} \rightleftharpoons \mathrm{AgOH}+\mathrm{HX}
$$

$\mathrm{X}$ denoting, $\mathrm{F}, \mathrm{Cl}, \mathrm{Br}$, or $\mathrm{I}$. The structure is shown in Fig. 6 .

This case is considerably more complicated than the previous case. When the two bonds are broken, the $\mathrm{AgOH}$ and $\mathrm{HX}$ molecules formed may separate. When those separated molecules join so that the $\mathrm{Ag}$ and $\mathrm{X}$ atoms occupy adjacent lattice sites, they will recombine to form $\mathrm{AgX}$. We have thus to consider two processes: the formation of $\mathrm{AgX}$ from $\mathrm{AgOH}$ and $\mathrm{HX}$, and the number of ways in which the broken bonds may be reformed. 
From the heat of vaporization of $\mathrm{HCl}$ in aqueous solution ${ }^{2}$ we know that each $\mathrm{HCl}$ molecule is surrounded by $10 \mathrm{H}_{2} \mathrm{O}$ molecules. We will assume that the $\mathrm{AgOH}$ molecule occupies two sites and that one $\mathrm{AgOH}$ molecule may replace one of those ten $\mathrm{H}_{2} \mathrm{O}$ molecules. Around the $\mathrm{HCl}$ molecule we may. thus consider 11 sites, two of which may be occupied by an AgOH molecule.

The number of pairs of $\mathrm{Ag}$ and $\mathrm{X}$ atoms per litre of the solution is then ${ }^{3}$

$$
\frac{11}{2} \cdot \frac{c_{\mathrm{AgOH}} \cdot c_{\mathrm{HX}}}{55.55}
$$

But this is the number of $\mathrm{AgX}$ molecules per litre. Hence,

$$
c_{\mathrm{AgX}}=\frac{11}{2} \cdot \frac{c_{\mathrm{AgOH}} \cdot c_{\mathrm{Hx}}}{55.55}
$$

or

$$
c_{\mathrm{AgOH}} \cdot c_{\mathrm{HX}}=\frac{2}{11} \cdot 55.55 c_{\mathrm{AgX}}
$$

We next consider the number of ways in which new bonds can be formed instead of the two broken bonds. There are $10 \mathrm{H}_{2} \mathrm{O}$. molecules with which the $\mathrm{Cl}$ atom may form bonds. The number of ways in which the two broken bonds may be reformed is thus $\left(\begin{array}{c}10 \\ 2\end{array}\right)=45$. The $O$ atom may, again, form 3 new bonds instead of the one broken. For the $\mathrm{Ag}$ atom we will assume that it may be surrounded by $10 \mathrm{H}_{2} \mathrm{O}$ molecules, just as is the $\mathrm{Cl}$ atom. This assumption is based upon the similarity of the structures of $\mathrm{HCl}$ and $\mathrm{NaOH}$ in aqueous solution 4 . Hence, the number of ways in which the broken bond may be reformed is 9 . The total number of ways in which the broken bonds can be reformed is thus $45 \times 3 \times 9=1215$ and

$$
\frac{1}{W}=1215
$$

Hence, from (27) and (28),

$$
c_{\mathrm{AgOH}}=c_{\mathrm{HX}}=\sqrt{2 \frac{55.55}{11 \times 1215} \cdot c_{\mathrm{AgX}}}=0.68 e^{-\frac{\Delta E_{s}}{2 R}\left(\frac{1}{T}-\frac{1}{T_{f}}\right)}
$$

in agreement with (18).

$$
\text { C. Solubility of } \mathrm{PbCl}_{2}
$$

We consider the equilibrium

$$
\mathrm{PbCl}_{2}+\mathrm{H}_{2} \mathrm{O} \rightarrow \mathrm{PbClOH}+\mathrm{HCl}
$$

according to Fig. 7 . 
This case differs from that of $\mathrm{AgCl}$ simply by the two $\mathrm{Cl}$ atoms and, accordingly, by a factor of 2 in $W$. Hence,

$$
c=0.68 \times \sqrt{2} e^{-\frac{\Delta E_{s}}{2 R}\left(\frac{1}{T}-\frac{1}{T}\right)}=0.96 e^{-\frac{\Delta E_{s}}{2 R}\left(\frac{1}{T}-\frac{1}{T}\right)}
$$

The agreement with the empirical formula (19) is not quite so good as in the previous cases. For $\mathrm{PbBr}_{2}$ we should have the same result (31) which differs from (20) by a factor of 1.8, however. The discrepancy may probably be attributed to complex formations or to an inadequate choice of $T_{f}$.

$$
\text { D. Solubility of } \mathrm{PbI}_{2}
$$

We consider the equilibrium

$$
\mathrm{PbI}_{2}+2 \mathrm{H}_{2} \mathrm{O} \rightleftharpoons \mathrm{Pb}(\mathrm{OH})_{2}+2 \mathrm{HI}
$$

according to Fig. 8 .

Comparing this case to that of $\mathrm{AgCl}$ we find

$$
W_{\mathrm{PbI}_{2}}=W_{\mathrm{AgCl} 1}^{2}
$$

and, thus,

$$
c_{\mathrm{Pb}(\mathrm{OH})_{3}}=\sqrt[3]{\left(2 \frac{55.55}{11 \times 215}\right)^{2} c_{\mathrm{PbI}_{2}}}=0.157 c^{-\frac{\Delta E_{s}}{3 R}\left(\frac{1}{T}-\frac{1}{T_{f}}\right)}
$$

in agreement with (21).

\section{THE SIGNIFICANCE OF $T_{f}$}

In deriving the formula (6) for an ideal solution we have disregarded chemical reactions, since otherwise the solution could not have been considered as ideal. The significance of $T_{f}$ is then the melting point of the solid. However, when reactions occur as illustrated in section 3 , the significance of $T_{f}$ is less obvious, since we have several salts in the solution, e.g. $\mathrm{AgCl}, \mathrm{AgOH}$, and $\mathrm{HCl}$. The significance of $T_{t}$ may therefore warrant some comments.

In order to bring all the salts into the liquid state we have to raise the temperature to the highest melting point. Thus, for such a mixture, the solute is the salt with the highest melting point, and the solvent is an aqueous solution of the salts of lower melting points. The significance of $T_{f}$ is then the melting point of this solute, $i . e . T_{f}$ is the highest melting point among those of the individual salts.

It follows from Fig. 1 that $T_{f}$ is the same for all the silver halides and about twice as high as the melting points of the halides. We may therefore assume that $T_{1}=1410^{\circ} \mathrm{K}$ is the melting point of the hydroxide, AgOH. There is no reason why the double hydroxide $(\mathrm{AgOH})_{2}$ should have a different melting

Acta Chem. Scand. 7 (1953) No. 10 
point; in fact, $\mathrm{AgOH}$ and $(\mathrm{AgOH})_{2}$ should be identical in the solid state. Henoe, $T_{t}=1410^{\circ} \mathrm{K}$ in the case of $\mathrm{Ag}_{2} \mathrm{O}$ as well.

For the lead salts $\mathrm{PbXOH}$ and $\mathrm{Pb}(\mathrm{OH})_{2}$ the melting points are not known, nor is $T_{f}$ the same for all the lead halides. We have therefore arbitrarily taken for $T$, the melting points of the halides. In view of the spread of the data as shown by the plots in Fig. 3, it is difficult to say whether the discrepancy between theoretical and empirical formulae is due to an erroneous choice of $T_{r}$. It should be pointed out, though, that in order to bring the empirical data in agreement with the theoretical formulae we have to chose lower values of $T_{f}$.

\section{CONCLUSIONS}

The agreement between theoretical and empirical formulae shows that the formula (6), valid for an ideal solution, is applicable to aqueous solutions of sparingly soluble salts, provided due corrections are made for the reactions involved in the process of dissolution. It further shows that the statistical computation of equilibrium constants is possible, provided the coordination numbers of the liquid structure are known.

There is no reason for applying the simple formula (6) to concentrated solutions, e.g. the solubility of alkali halides, since those do not follow Raoult's law. Hence, for concentrated solutions, $X$ should be replaced by the actual

$$
-\frac{\Delta F_{m}}{R T}
$$

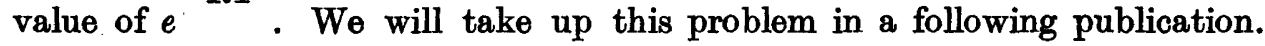

Acknowledgment. The results reported in this paper were obtained in the Laboratory of Avesta Jernverks AB, Sweden. I am indebted to the Management of the Company for permission to publish this report.

\section{REFERENCES}

1. Berg, T. G. O. Appl. Sci. Research B, 4 (1954). In press.

2. Berg, T. G. O. Acta Chem. Scand. 7 (1953) 1045.

3. Guggenheim, E. A. Mixtures, Oxford Univ. Press, Oxford 1952.

4. Finbak, Chr. Tidskr. Kjemi, Bergvesen, Met. 3 (1943) 36.

Received June 2, 1953. 